\title{
Experimental Dielectric Measurements for Cost-fewer Polyvinyl Chloride Nanocomposites
}

\author{
Ahmed Thabet*, Youssef Mobarak** \\ * Nano-Technology Research Centre, Faculty of Energy Engineering, Aswan University \\ ** Departement of Electrical Engineering, Faculty of Engineering, Rabigh, King AbdulazizUniversity \\ ** Departement of Electrical Engineering, Faculty of Energy Engineering, Aswan University
}

\begin{tabular}{l} 
Article Info \\
\hline Article history: \\
Received Sep 23, 2014 \\
Revised Nov 27, 20 \\
Accepted Dec 14, 2014 \\
\hline Keyword: \\
Dielectric materials \\
Insulation \\
Nano-composite \\
Nanoparticles \\
Polymers
\end{tabular}

\begin{abstract}
Polymer nanocomposites possess promising high performances as engineering materials, if they are prepared and fabricated properly. In this research, it has been processed samples of nanocomposite polymers as electrical insulating materials for application on the electric power cables by using the latest techniques of nanotechnology. This paper has been investigated enhanced dielectric and electrical properties of Polyvinyl chloride PVC as matrix have shown that trapping properties are highly modified by the presence of costless nanofillers clay and fumed silica. An experimental work for dielectric loss and capacitance of the new nanocomposite materials have been investigated and compared with unfilled industrial materials. It is found that a good correlation exists in respect of capacitance and dielectric loss values measured with percentage of nanofillers. Thus, it has been investigated the influence of costless nanofillers material and its concentration on dielectric properties of industrial polymersbased composite systems. A comparative study is performed between the unfilled base polymers, the systems containing one type of nanoparticles clayor fumed silica inside the host polymer with various concentrations.
\end{abstract}

Copyright (C) 2015 Institute of Advanced Engineering and Science. All rights reserved.

\section{Corresponding Author:}

Ahmed Thabet, Youssef Mobarak

Nano-Technology Research Centre,

Faculty of Energy Engineering, Aswan University,

Aswan, 81528, Egypt

Email: athm@aswu.edu.eg, ysoliman@kau.edu.sa

\section{INTRODUCTION}

Polymer nanocomposites are defined as composites in which small amounts of nanometer sized fillers are homogenously dispersed in polymers by several weight percentages wt $\%$. As defined, the fillers added to the matrix are very small in quantity, normally less than $10 \mathrm{wt} \%$. In order to grasp a better understanding on polymer nanocomposites, Tanaka et al. [1] have sought to further compare it with polymer microcomposites in another two major aspects, namely the size of the fillers and the specific surface area of the composites. Nanocomposites are in the range of nanometers in size (less than $100 \mathrm{~nm}$ ), different with three orders of magnitude in length as compared to microcomposites. This would mean a difference of approximately nine orders in their number density. Therefore, the distance between neighbouring fillers are much smaller in nanocomposites than in microcomposites. In terms of specific surface area, nanocomposites have high specific surface area of fillers (about three orders larger than microcomposites). With this, the interaction of polymers matrices with fillers is expected to be much more in nanocomposites. While the conventional microcomposites can alter certain desired properties of the composite materials (e.g. mechanical and thermal properties), it often comes with the compromise of other properties being negatively affected (e.g. electrical properties). Interestingly, the newly emerging polymer nanocomposites provide significant improvements in combined electrical, thermal and mechanical properties [2]-[4]. 
These profound impacts create great benefits specifically to the high voltage insulating industry, especially in electrical properties enhancement. Although polymer nanocomposites have drawn research interest in high voltage electrical insulating society, the fundamental physics and chemistry leading to the property enhancement is poorly understood and much remains unexplored. Polymeric materials have become an integral part of electric and electronic packaging systems today due to their excellent thermal, chemical, and dielectric properties apart from their easy processability and low cost [5], [6]. For the enhancement of insulation reliability and compact design in electric power apparatus, the electrical properties of polymer composites with inorganic fillers in the polymer matrix play an important role. Recently, it has been recognized that nanoparticle fillers have benefit for avoiding the degradation of insulation in long-term characteristics [7], [8].

Nanotechnologies are present in a lot of domain since they are a great source of innovation. They may have a powerful impact on development of advanced electrical and electronic device. In the case of nanocomposite, it has been reported that a few percent of functional nanofiller can improve mechanical characteristic permeability characteristic and electrical properties. Many papers discussing the general overview, theory and the functionality of nanocomposite dielectrics have been published [9]-[15]. The way to disperse nanofillers layer in polymer matrix at a nanometric level is still under optimization, hut good results in terms of orientation, control of interaction between host material and nanograin (intercalation, exfoliation) have been achieved already [10]. The use of nanoadditives in dielectric materials has made great progress in the last few years [11]-[12]. The addition of inorganic nanoparticles into polymer (polymer nanocomposite) has been studied and applied to engineering materials for industrial products to improve various properties of material [13]. It has been reported that the polymer nanocomposite has abilities to improve the dielectric properties of base material [14]. The characteristics of polymer nanocomposite for electrical and dielectric properties were also studied to ensure the high reliability of the insulating system [15]. The effective properties of dielectric mixtures have been investigated mathematically and experimentally for prediction of effective dielectric properties [16]-[25].

In recent decades, the use of polymers as electrical insulating materials has been growing rapidly [26], [27]. The base polymer properties have been developed by adding small amounts of different fillers but they are expensive to the polymer material. Recently, great expectations have focused on costless nanofillers [26]. However, there are few papers concerning the effect of types of costless nanofillers on electrical properties of polymeric nanocomposite [29], [30]. With a continual progress in polymer nanocomposites, this research depicts the effects of types and concentration of costless nanoparticles in electrical properties of industrial polymer material. All experimental results have been investigated and discussed to detect all effects of nanofillers on electrical properties of nanocomposite industrial material which fabricated; like PP, and PVC with various nanofillers of clay and fumed silica.

In this study, polyvinylchloride and cost-fewer nanoparticles (clay and fumed silica) were processed and characterized. Materials selection and electrical/mechanical predictable models have been carried out using Cambridge Engineering Selector (CES) program. It was found that nanofillers of fumed silica have an adverse influence on dielectric properties of PVC composites while clay nanoparticles improved the electrical insulation properties. Therefore, surface analysis and nano montmorillonite were examined using scanning electron microscope to be sure that the penetration homogeneity of cost-fewer nanoparticles inside polyvinyl chloride insulation materials. Dielectric properties were assessed using HIOKI 3522-50 LCR Hitester device. An experimental work for dielectric loss and capacitance of the new nanocomposite materials have been investigated and compared with unfilled industrial materials in a frequency range of $1 \mathrm{~Hz}-0.1$ $\mathrm{MHz}$.

\section{EXPERIMENTAL SETUP}

HIOKI 3522-50 LCR Hi-tester device as shown in Fig.(1) has been measured electrical parameters of nano-metric solid dielectric insulation specimens at various frequencies: $|\mathrm{Z}|,|\mathrm{Y}|, \theta, \mathrm{Rp}(\mathrm{DCR})$, Rs (ESR, DCR),G, X, B, Cp, Cs, Lp, Ls, D (tan $\delta)$, and Q. Specification of LCR is Power supply: 100, 120, 220 or 240 $\mathrm{V}( \pm 10 \%) \mathrm{AC}$ (selectable), 50/60 Hz, and Frequency: DC, $1 \mathrm{mHz}$ to $100 \mathrm{kHz}$, Display Screen: LCD with backlight $/ 99999$ (full 5 digits), Basic Accuracy: Z: $\pm 0.08 \%$ rdg. $\theta: \pm 0.05^{\circ}$, and External DC bias $\pm 40 \mathrm{~V}$ max.(option) (3522-50 used alone $\pm 10 \mathrm{~V}$ max./ using $9268 \pm 40 \mathrm{~V}$ max.). Finally, It can be measured all dielectric properties for pure and nanocomposite industrial materials by using HIOKI 3522-50 LCR Hi-tester device and have been detected as shown in results and discussion. 


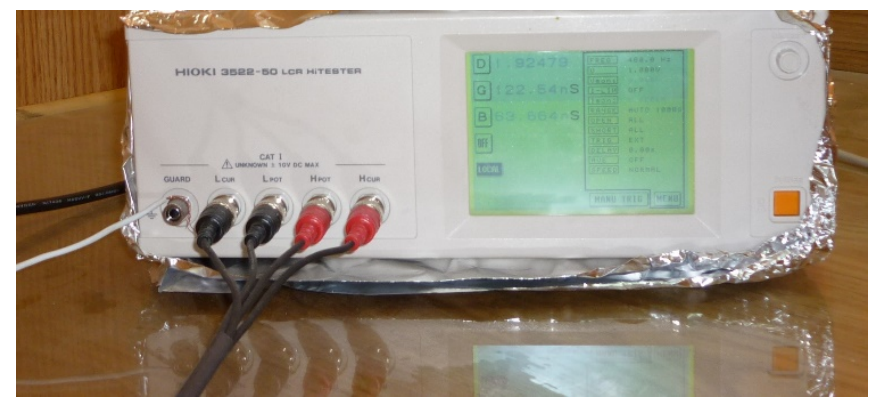

Figure 1. Life photo for experimental HIOKI 3522-50 LCR Hi-tester device equipment's

\section{RESULTS AND ANALYSIS}

The industrial nanocomposites materials studied here is PVC that has been formulated utilizing nanoparticulates. The base of all these polymer materials is a commercially available material already in use in the manufacturing of high-voltage HV industrial products and their properties detailed in Table 1. Additives of nanoparticles to the base industrial polymers has been fabricated by using mixing, ultrasonic, and soft heating processes in Nano-technology Research Centre, Aswan, Egypt. Preparation of studied polymers has been used SOL-GEL method. The sol-gel processing of the nanoparticles inside the polymer dissolved in non-aqueous or aqueous solution is the ideal procedure for the formation of interpenetrating networks between inorganic and organic moieties at the milder temperature in improving good compatibility and building strong interfacial interaction between two phases. This process has been used successfully to prepare nanocomposites with nanoparticles in a range of polymer matrices. Several strategies for the sol-gel process are applied for formation of the hybrid materials. One method involves the polymerization of organic functional groups from a preformed sol-gel network. The sol- gel process is a rich chemistry which has been reviewed elsewhere on the processing of materials from glass to polymers. The organic-inorganic hybrid nanocomposites comprising of polymer, and nanoparticles were synthesized through sol-gel technique at ambient temperature. The inorganic phase was generated in situ by hydrolysis-condensation of tetraethoxysilane TEOS in different concentrations, under acid catalysis, in presence of the organic phase, polymer, dissolved in formic acid [29].

\begin{tabular}{ccc} 
Table 1. Dielictric Properties of Pure and Nano-composite Materials \\
\hline Materials & $\begin{array}{c}\text { Dielectric } \\
\text { constant at } 1 \mathrm{kHz}\end{array}$ & $\begin{array}{c}\text { Resistivity } \\
(\Omega . m)\end{array}$ \\
\hline Pure PVC & 3.3 & $10^{13}$ \\
PVC + 1\%wt Clay & 3.20 & $10^{14}$ \\
PVC + 5\%wt Clay & 2.83 & $10^{14}-10^{17}$ \\
PVC + 10\%wt Clay & 2.49 & $10^{17}-10^{20}$ \\
PVC + 1\%wt Fumed Silica & 3.35 & $10^{12}$ \\
PVC + 5\%wt Fumed Silica & 3.42 & $10^{12}-10^{10}$ \\
\hline
\end{tabular}

\subsection{Properties of Nanofillers}

Nanofillers of clay are nanomer 1.30E, Cost-less clay catalyst is the best filler among nanofillers industrial materials. The main constituent of nanofiller clays significant quantities of other nanoclays can often be present. Spherical particle shape is the most important characteristic of nanoclay for polymer applications. The platy nature means that clay fillers have a greater effect on properties such as viscosity, stiffness and strength, using clay as nanofiller gives high levels of flame retardancy to the produced composite, and it's selected in this study. Cost less of clay catalyst to be the best filler among nano-fillers industrial materials [24]-[27]. Nanofillers of fumed silica are a fluffy white powder with an extremely low density, marketed under trade names such as Aerosil and Cab-o-sil. With both hydrophobic and hydrophillic grades available, it is widely used as a rheology modifier, imparting highly thixotropic properties at relatively low percentages. It can also provide increased track, better stability in suspensions and prevents "sagging" and settling of solids in a liquid system. For this reason it is particularly suitable for coatings, inks, adhesives, resins, sealants, and greases. Fumed silica, or fumed silicon dioxide, is produced by the vapor-phase hydrolysis of silicon tetrachloride in an $\mathrm{H}_{2} / \mathrm{O}_{2}$ flame. Hydrophilic fumed silica bearing hydroxyl groups on its surface is produced by this process. Fumed silica powders used in paints and coatings, silicone rubber and 
silicone sealants, adhesives, cable compounds and gels, printing inks and toner, and plant protection [28][30].

\subsection{Properties of Industrial Polymers}

PVC is the most widely used of any of the thermoplasts, polymerized vinyl chloride, and which is produced from ethylene and anhydrous hydrochloric acid. PVC is stronger and more rigid than other general purpose thermoplastic materials. It has a high tensile strength and modulus of elasticity. Additives are used to further specific end uses, such as thermal stabilizers, lubricity, impact modifiers, and pigmentation. There are two basic forms of PVC rigid and plasticized. Rigid PVC, as its name suggests, is an unmodified polymer and exhibits high rigidity. Unmodified PVC is stronger and stiffer than PE and PP. Plasticized PVC is modified by the addition of a low molecular weight species to flexibilize the polymer. Plasticized PVC can be formulated to give products with rubbery behaviour. It is modified by the addition of styrene butadiene rubber which improves notch toughness and impact strength. PVC's are basically tough and strong, resist water and abrasion, and are excellent electrical insulators [14], [30].

\subsection{Properties of Industrial Polymers and Nanofillers}

PVC is the most widely used of any of the thermoplasts, polymerized vinyl chloride, and which is produced from ethylene and anhydrous hydrochloric acid. PVC is stronger and more rigid than other general purpose thermoplastic materials. It has a high tensile strength and modulus of elasticity. The main constituent of nanofillers of clay significant quantities of other nanoclays can often be present. Spherical particle shape (Dia.:10nm) is the most important characteristic of clay and fumed silica nanoparticles which used for nanocomposites polymer applications in this research. The platy nature means that clay fillers have a greater effect on properties such as viscosity, stiffness and strength, using clay as nanofiller gives high levels of flame retardancy to the produced composite, and it's selected in this study.

The distribution of nanoparticles within polymer matrix has been detected by using scanning electron microscope (SEM) as shown in Figure 2, and Figure 3 respectively.Fabricated and testing nanocomposite industrial materials have been done by using all experimental setup and equipment's in NanoTechnologyResearch Center. Dielectric Spectroscopy is a powerful experimental method to investigate the dynamical behavior of a sample through the analysis of its frequency dependent dielectric response. This technique is based on the measurement of the capacitance as a function of frequency of a sample sandwiched between two electrodes. The $\tan \delta$, and capacitance $\mathrm{C}$ were measured as a function of frequency in the range $10 \mathrm{~Hz}$ to $50 \mathrm{kHz}$ at $25{ }^{\circ} \mathrm{C}$ for all the test samples. The measurements were made using high resolution dielectric spectroscopy.

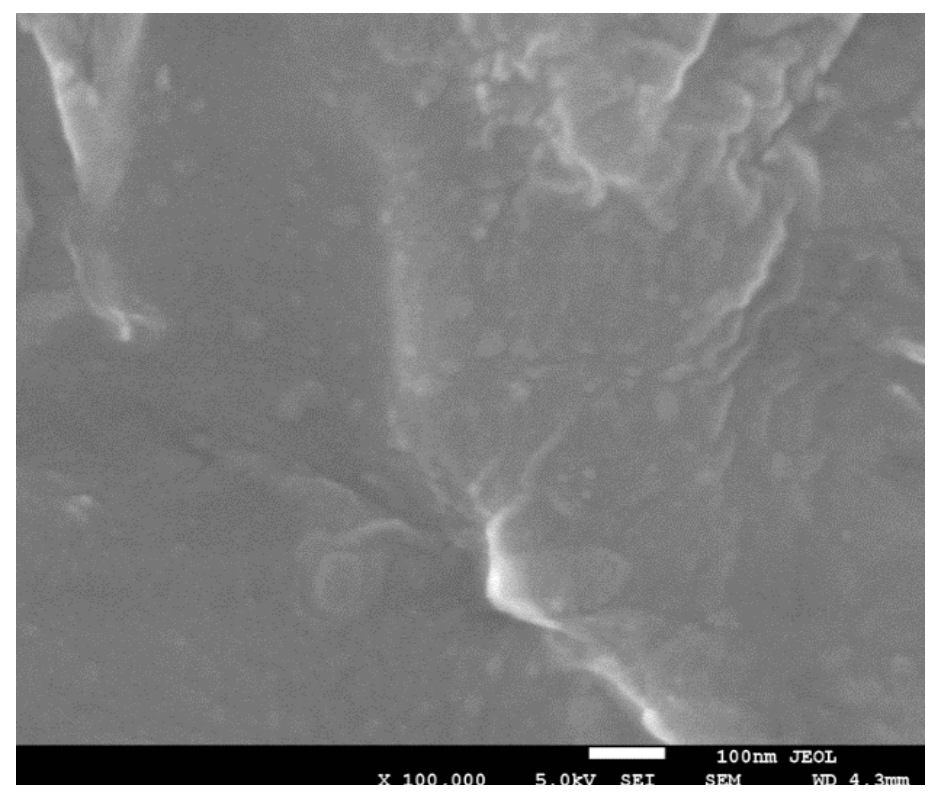

Figure 2. SEM images for dispersion of clay and fumed silica nanoparticles in PVC (Clay/PVC nanocomposites) 


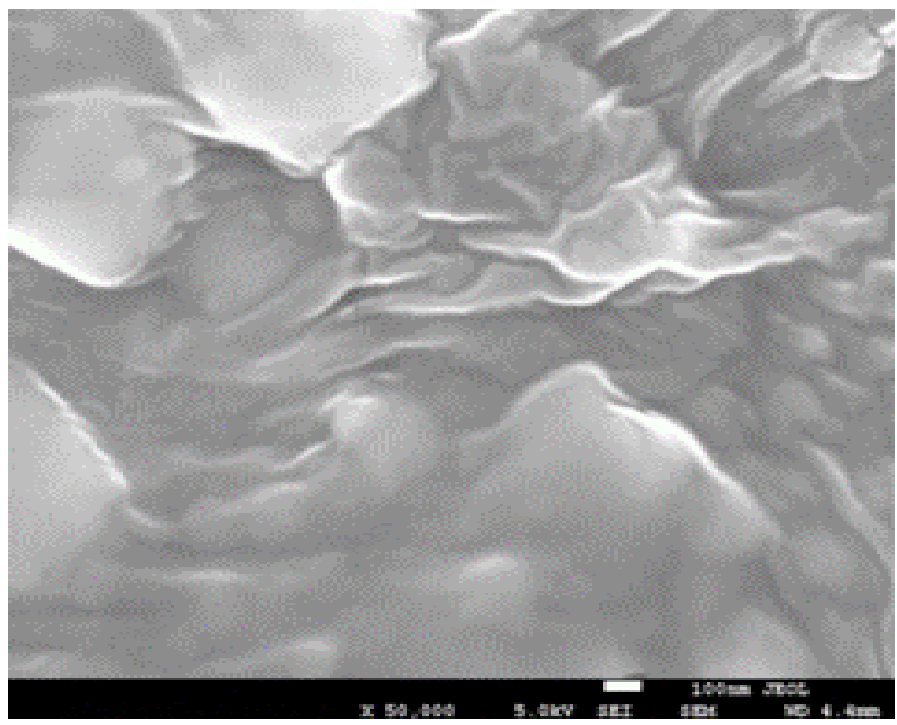

Figure 3. SEM images for dispersion of clay and fumed silica nanoparticles in PVC (Fumed Silica/PVC nanocomposites)

\section{Predictable Mechanical and Electrical}

Figure 4 illustrates the electrical and mechanical properties of Clay/PVC nanocomposites using CES software [31, 32]. The initial results using the predictable model (CES-Software) showed that addition of clay particles to PVC can cause increasing in electrical resistivity and modulus of elasticity. The clay fillers loading are between 1 to $70 \% \mathrm{wt} / \mathrm{wt}$. Electrical resistivity was increased from $1.1 \times 10^{9}$ to $9 \times 10^{10} \mathrm{ohm} . \mathrm{m}$ (mean value). Modulus of elasticity was improved significantly from $3.190 \mathrm{GPa}$ to $93.30 \mathrm{GPa}$ with respect to clay fillers loading 1 to $70 \% \mathrm{wt} / \mathrm{wt}$. Whatever, Figure 5 shows the electrical and mechanical properties of Fumed silica/PVC nanocomposites by using CES software. Addition of silica to PVC leads to improve electrical resistivity of PVC. It is detected that the electrical resistivity can be increased up to $5.0 \times 1010$ Ohm.m (mean value) using 70\% Silica wt/wt. This can be attributed to the high electrical resistivity of silica $(1.0 \times 1012-1.0 \times 1013 \mathrm{ohm} . \mathrm{m})$ comparing with lower electrical resistivity value of PVC matrix $\left(3.16 \times 10^{9}-\right.$ $\left.3.16 \times 10^{9} \mathrm{ohm} . \mathrm{m}\right)$. Modulus of elasticity of PVC was increased from $3 \mathrm{GPa}$ to $72 \mathrm{GPa}$ in the presence of $70 \%$ wt/wt silica.

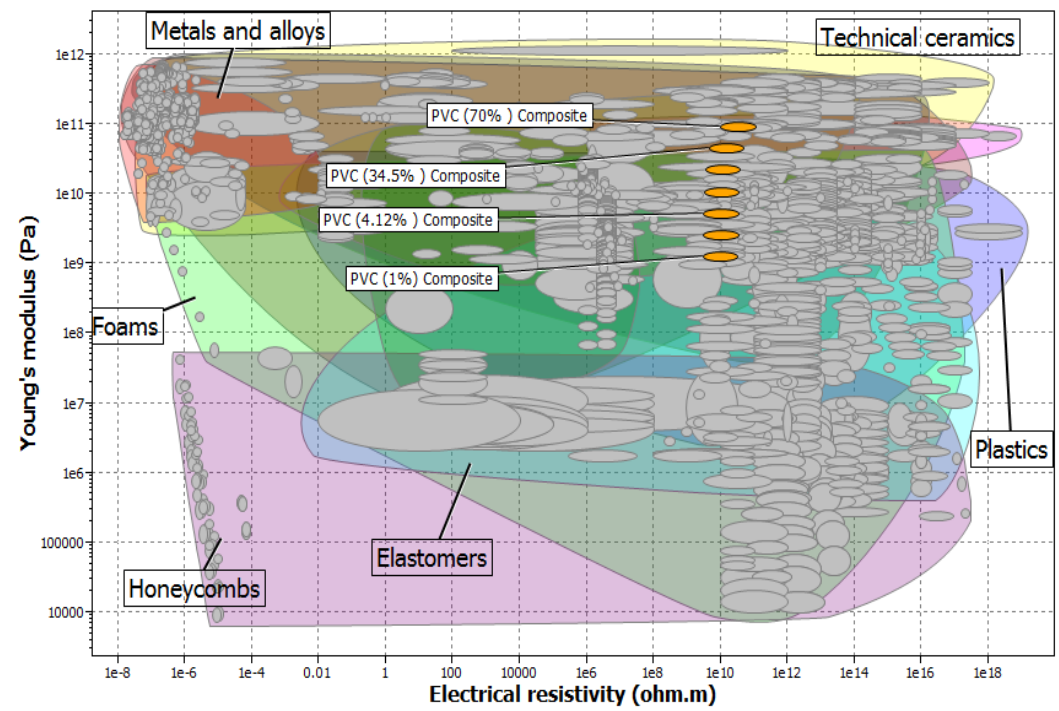

Figure 4. Electrical resistivity and mechanical properties of PVC-Clay using CES program 


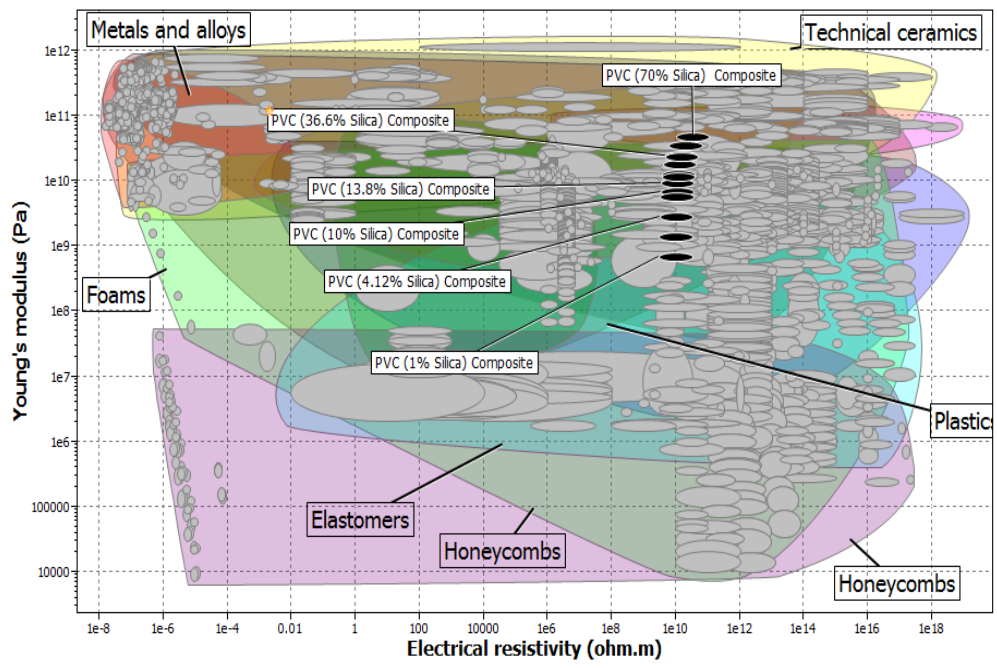

Figure 5. Electrical resistivity and mechanical properties of PVC- Silica using CES program

\section{Results and Discusion}

Figure 6 shows loss tangent as a function of frequency for Clay/PVC nanocomposites at room temperature $\left(25^{\circ} \mathrm{C}\right)$. Also, this figure contrasts the measured loss tangent with rising percentage of clay nanofillers in new nanocomposite. It is cleared that, the loss tangent of Clay/PVC nanocomposites decreases with increasing frequency but, it increases with increasing clay percentage nanofillers up to $10 \%$ wt Clay. Figure 7 shows capacitance as a function of frequency for Clay/PVC nanocomposites at room temperature $25^{\circ} \mathrm{C}$. Also, this figure contrasts the measured capacitance with rising percentage of clay nanofillers in the nanocomposite. It is cleared that, the capacitance of Clay/PVC nanocomposites decreases with increasing frequency and increases with increasing clay percentage nanofillers up to $1 \%$ wt. But, it is noticed that, the capacitance of Clay/PVC nanocomposites decreases with increasing clay percentage nanofillers from $1 \% \mathrm{wt}$ up to $10 \%$ wt. Figure 8 shows loss tangent as a function of frequency for Fumed Silica/PVC nanocomposites at room temperature $\left(25^{\circ} \mathrm{C}\right)$. Also, this figure contrasts the measured loss tangent with rising percentage of fumed silica nanofillers in new nanocomposites. It is illustrates that, the loss tangent of PVC decreases with increasing frequency but it increases at high frequencies. And so, loss tangent of Fumed Silica/PVC nanocomposites decreases with increasing fumed silica percentage nanofillers up to 5\% fumed silica. Also, it is noticed that, the loss tangent of Fumed Silica/PVC nanocomposites increases with increasing fumed silica percentage nanofillers from $5 \%$ wt. up to $10 \%$ wt. fumed silica nanoparticles. Figure 9 shows capacitance as a function of frequency for fumed silica/PVC nanocomposites. Also, this figure contrasts the measured capacitance with rising percentage of fumed silica nanofillers in the new nanocomposite. It is depicted that, the capacitance of fumed silica/PVC nanocomposites decreases with increasing frequency and decreases with increasing fumed silica percentage nanofillers up to $5 \% \mathrm{wt}$. But, it is noticed that, the capacitance of fumed silica/PVC nanocomposites increases with increasing fumed silica percentage nanofillers from $5 \% \mathrm{wt}$ up to $10 \%$ wt. 


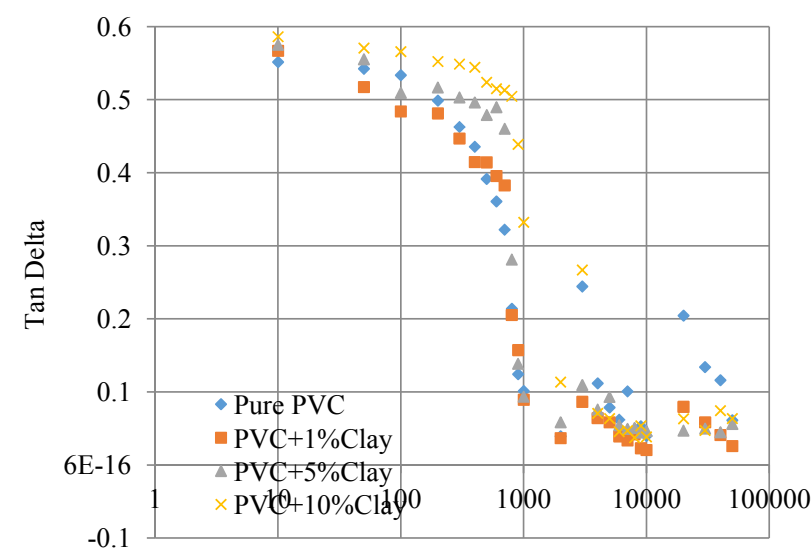

Frequency (Hz)

Figure 6. Measured loss tangent as a function of frequency for Clay/PVC nanocomposites at room temperature $\left(25^{\circ} \mathrm{C}\right)$

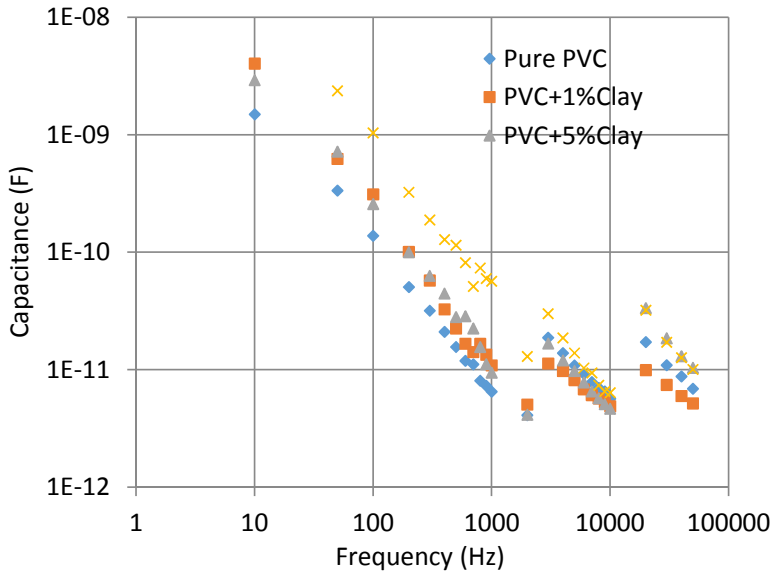

Figure 7. Measured capacitance as a function of frequency for Clay/PVC nanocomposites at room temperature $\left(25^{\circ} \mathrm{C}\right)$

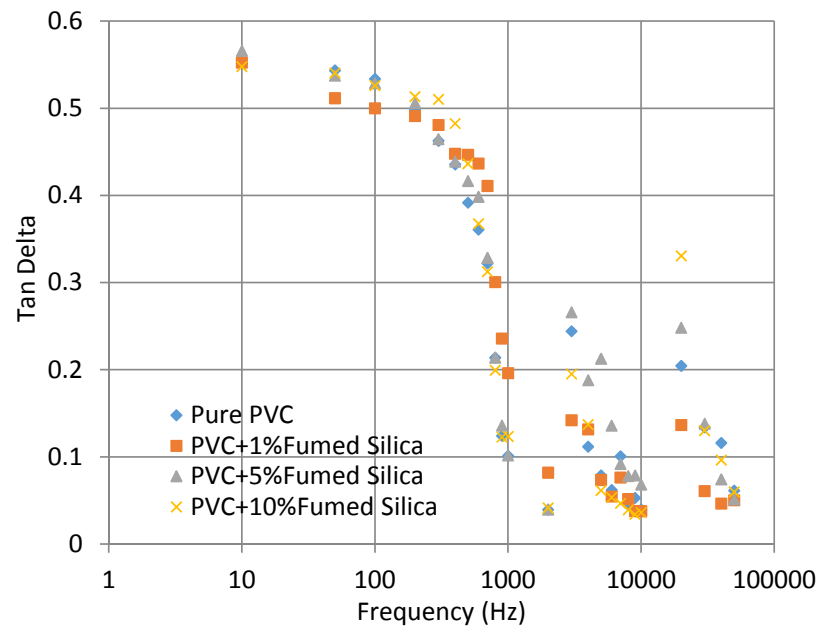

Figure 8. Measured loss tangent as a function of frequency for Fumed Silica/PVC nanocomposites at room temperature $\left(25^{\circ} \mathrm{C}\right)$ 


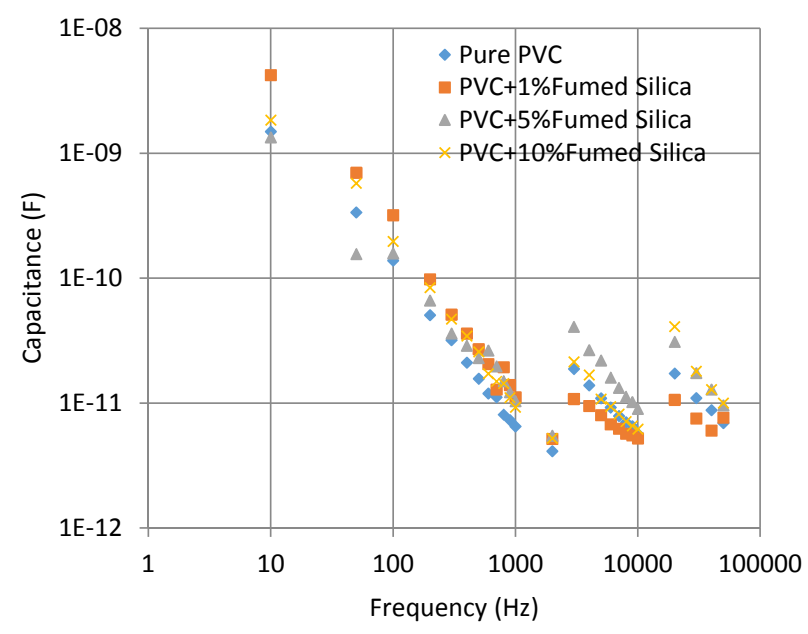

Figure 9. Measured capacitance as a function of frequency for Fumed Silica/PVC nanocomposites at room temperature $\left(25^{\circ} \mathrm{C}\right)$

\section{CONCLUSION}

Adding clay nanoparticles to polypropylene and polyvinyl Chloride is decreasing permittivity and increasing the resistivity of the polymer, while adding fumed silica nanoparticles is increasing permittivity and decreasing the resistivity of the polymer. Increasing percentage clay nanoparticles increases the loss tangent and capacitance of polypropylene nanocomposites. On the other wise, increasing percentage clay nanoparticles up to $1 \% \mathrm{wt}$ increases the loss tangent and capacitance of Polyvinyl chloride nanocomposites. But, the capacitance of Polyvinyl chloride decreases with increasing clay percentage nanofillers from $1 \% \mathrm{wt}$ up to $10 \%$ wt. Increasing fumed silica nanoparticles up to $5 \% \mathrm{wt}$ in polypropylene nanocomposites increases loss tangent and capacitance, but it decreases with increasing fumed silica nanoparticles up to $10 \%$ wt. On the other wise, increasing fumed silica nanoparticles up to $5 \% \mathrm{wt}$ in polyvinyl chloride nanocomposites decreases loss tangent and capacitance, but it increases with increasing fumed silica nanoparticles up to $10 \%$ wt.

\section{ACKNOWLEDGEMENTS}

The present work was supported by the Science and Technology Development Fund (STDF), Egypt, Grant No: Project ID 505.

\section{REFERENCES}

[1] Tanaka, T., Montanari, G.C., and Mülhaupt, R. "Polymer Nanocomposites as Dielectrics and Electrical InsulationPerspectives for Processing Technologies, Material Characterization and Future Applications", IEEE Transactions on Dielectrics and Electrical Insulation, Vol.11, No. 5, pp. 763-784, 2004.

[2] Cao, Y., Irwin, P.C., and Younsi, K., "The Future of Nanodielectrics in the Electrical Power Industry", IEEE Transactions on Dielectrics and Electrical Insulation, Vol. 11, No. 5, pp. 797-807, 2004.

[3] M.A. Abd Allah, Sayed A. Ward, and Amr A. Youssef, "Effect of Functionally Graded Material of Disc Spacer with Presence of Multi-Contaminating Particles on Electric Field inside Gas Insulated Bus Duct", International Journal of Electrical and Computer Engineering (IJECE), Vol. 3, No. 6, December 2013, pp. 831-848.

[4] Hamdy Mohamed Soliman and S.M. El. Hakim, "Optimum Remedial Operation of Permanent MagnetSynchronous Motor", International Journal of Electrical and Computer Engineering (IJECE), Vol.2, 2012, pp.621-631.

[5] A. Sluzalec, "Stochastic finite elements in optimization of powder metallurgy materials," Mechanics Based Design of Structures and Machines, Vol.40, No.1, pp. 33-41, 2012.

[6] A. Sluzalec, "Stochastic sensitivity in metal forming of rigidporoplastic materials," Structural and Multidisciplinary Optimization, Vol.45, No. 1, pp. 139-145, 2012.

[7] Eugen COCA, Valentin POPA, "Antenna Radiation Pattern Influence on the Localization Accuracy in Wireless Sensor Networks", Advances in Electrical and Computer Engineering, Vol. 13, pp. 43-46, No. 2, 2013.

[8] A. Thabet, Youssef A. Mobarak, "Experimental Study for Dielectric Strength of New Nanocomposite Polyethylene Industrial Materials", International Journal of Electrical Engineering and Technology (IJEET), Vol. 3, Issue 1, pp. 553-564, Jan- June 2012.

[9] J.I. Hong, L.S. Schadler, R.W. Siegel, E. Martensson, "Rescaled Electrical Properties of ZnO/Low Density Polyethylene Nanocomposites” Applied Physics Letters, Vol.82 Issue. 12, pp. 1956 - 1958, Mar 2003. 
[10] G.C. Montanari, D. Fabiani, F. Palmieri, D. Kaempfer, R. Thomann and R. M"ulhaupt, "Modification of Electrical Properties and Performance of EVA and PP Insulation through Nanostructure by Organophilic Silicates" IEEE Transactions on Dielectrics and Electrical Insulation Vol. 11, No. 5; pp. 754-762, October 2004.

[11] T. Tanaka, "Dielectric Nanocomposites with Insulating Properties" IEEE Transactions on Dielectrics and Electrical Insulation Vol. 12, No. 5, pp. 914-928, October 2005.

[12] N. Shi and R. Ramprasad, "Local Properties at Interfaces in Nanodielectrics: An abinitio Computational Study" IEEE Transactions on Dielectrics and Electrical Insulation Vol. 15, No. 1, pp. 170-177, February 2008.

[13] X.Y. Huang, P.K. Jiang, C.U. Kim, "Electrical Properties of Polyethylene/Aluminum Nanocomposites" Journal of Applied Physics, Vol. 102, Issue 12, pp. 124103 - 124103-8, Dec 2007.

[14] Z. Dang, B. Xia, Sh. Yao, M. Jiang, H. Song, L. Zhang, D. Xie, "High-Dielectric-Permittivity High-Elasticity Three-Component Nanocomposites with Low Percolation Threshold and Low Dielectric Loss" Journal of Applied Physics Letters, Vol. 94, Issue 4, pp. 42902 - 42902-3, Jan 2009.

[15] X. Huang, Ch. Kim, P. Jiang, Y. Yin, Z. Li, "Influence of Aluminum Nanoparticle Surface Treatment on The Electrical Properties of Polyethylene Composites" Journal of Applied Physics, Vol.105, Issue 1, pp. 14105 - 14105 10, Jan 2009.

[16] A. Thabet, and Y.A. Mobarak, "Novel Nanocomposite Insulation Materials for the Enhancing Performance of Power Cables" 21st, International Conference and Exhibition on Electricity Distribution (CIRED-2011), Frankfurt, Germany, June 6-9, 2011.

[17] Ion R. STANCIU, Florin MOLNAR-MATEI, "Detecting Power Voltage Dips Using Tracking Filters - A Comparison Against Kalman", Advances in Electrical and Computer Engineering, Vol. 12, No. 4, pp. 77-82, 2012.

[18] M. Roy, J.K. Nelson, R.K. MacCrone, L.S. Schadler, C.W. Reed, R. Keefe, "Polymer Nanocomposite Dielectricsthe Role of the Interface" IEEE Transactions onDielectrics and Electrical Insulation, Vol. 12 Issue 4, pp. 629 643, Aug. 2005.

[19] V. Tomer, G. Polizos, C.A. Randall, E. Manias, "Polyethylene Nanocomposite Dielectrics: Implications of Nanofiller Orientation on High Field Properties and Energy Storage" Journal of Applied Physics, Vol. 109 Issue 7, pp. 74113 - 74113-11, Apr 2011.

[20] Y. Murakami, M. Nemoto, S. Okuzumi, S. Masuda, M. Nagao, N. Hozumi, Y. Sekiguchi, "DC Conduction and Electrical Breakdown of MgO/LDPE Nanocomposite" IEEE Transaction on Dielectrics and Electrical Insulation, Vol. 15 Issue 1, pp. 33 - 39, February 2008.

[21] G.D. Liang and S.C. Tjong, "Electrical Properties of Percolative Polystyrene/Carbon Nanofiber Composites" IEEE Transactions on Dielectrics and Electrical Insulation Vol. 15, No. 1; pp. 214-220, February 2008.

[22] M.G. Veena, N.M. Renukappa, S. Seetharamu, P. Sampathkumararr, "Effect of Nanofiller at Low Frequency behavior of Dielectric Insulator" IEEE, Proceedings of the 9th International Conference on Properties and Applications of Dielectric Materials July 19-23, Harbin, China, 2009.

[23] K. Ishimoto, E. Kanegae, Y. Ohki, T. Tanaka, Y. Sekiguchi, Y. Murata and C. C. Reddy, "Superiority of Dielectric Properties of LDPE/MgONanocomposites over Microcomposites" IEEE Transactions on Dielectrics and Electrical Insulation Vol. 16, No. 6; pp. 1735-1742, December 2009.

[24] K.S. Shah, R.C. Jain, V. Shrinet, A.K. Singh, D.P. Bharambe, "High Density Polyethylene (HDPE) Clay Nanocomposite for Dielectric Applications" IEEE Transactions on Dielectrics and Electrical Insulation Vol. 16, No. 3;pp 853 - 861, 2009.

[25] L.A. Utracki, "Clay-Containing Polymeric Nanocomposites and their Properties" IEEE, Electrical Insulation Magazine, Vol. 26, Issue 4, pp. 8, July 2010.

[26] N. Fuse, Y. Ohki, and T. Tanaka, "Comparison of Nano-structuration Effects in Polypropylene among Four Typical Dielectric Properties" IEEE Transactions on Dielectrics and Electrical Insulation Vol. 17, No. 3;pp. 671-677, June 2010.

[27] M. Takala, H. Ranta, P. Nevalainen, P. Pakonen, J. Pelto, M. Karttunen, S. Virtanen, V. Koivu, M. Pettersson, B. Sonerud and K. Kannus, "Dielectric Properties and Partial Discharge Endurance of Polypropylene-Silica Nanocomposite", IEEE Transactions on Dielectrics and Electrical Insulation, Vol. 17, No. 4; pp. 1259-1267, August 2010.

[28] M. Amhid, D. Mary, G. TeyssedreI, C. Laurent, G. C. Montanari, D. Kaempfer, R. Miilhaupt, "Effect of Filler Concentration on Dielectric Behaviour and on Charge Trapping in PP/clay Nanocomposite" IEEE, Annual Report Conference on Electrical Insulation and Dielectric Phenomena, 2004.

[29] L. Bois, F. Chassagneux, S. Parola, F. Bessueille. "Growth of Ordered Silver Nanoparticles in Silica Film Mesostructured with a Triblock Copolymer PEO-PPO-PEO” Journal of Solid State Chemistry Vol. 182, pp. 1700$1707,2009$.

[30] A. Thabet, Y.A. Mobarak, "Dielectric Characteristics of New Nano-Composite Industrial Materials" International Conference on High Voltage Engineering and Application (ICHVE-2010), New Orleans, pp. 568-571, October 1114, 2010.

[31] M. Takala, H. Ranta, P. Nevalainen, P. Pakonen, J. Pelto, M. Karttunen, S. Virtanen, V. Koivu, M. Pettersson, B. Sonerud and K. Kannus, "Dielectric Properties and Partial Discharge Endurance of Polypropylene-Silica Nanocomposite", IEEE Transactions on Dielectrics and Electrical Insulation, Vol. 17, No. 4; pp. 1259-1267, August 2010.

[32] Youssef A. Mobarak, M. Bassyouni, and M. Almatawa, "Materials Selection, Synthesis, and Dielectrical Properties of PVC Nanocomposites", Advances in Materials Science and Engineering, Vol. 2013, Article ID 149672, 6 pages, 2013. 


\section{BIOGRAPHIES OF AUTHORS}

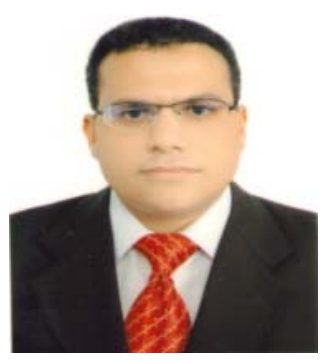

Ahmed Thabet was born in Aswan, Egypt in 1974. He received the BSc (FEE) Electrical Engineering degree in 1997 and MSc (FEE) Electrical Engineering degree in 2002 both from Faculty of Energy Engineering, Aswan, Egypt. PhD degree had been received in Electrical Engineering in 2006 from El-Minia University, Minia, Egypt. He joined with Electrical Power Engineering Group of Faculty of Energy Engineering in Aswan University as a Demonstrator at July 1999, until; he held Associate Professor Position at October 2011 up to date. His research interests lie in the areas of analysis and developing electrical engineering models and applications, investigating novel nano-technology materials via addition nano-scale particles and additives for usage in industrial branch, electromagnetic materials, electroluminescence and the relationship with electrical and thermal ageing of industrial polymers. Many of mobility's have investigated for supporting his research experience in UK, Finland, Italy, and USA ...etc. On 2009, he had been a Principle Investigator of a funded project from Science and Technology development Fund "STDF" for developing industrial materials of ac and dc applications by nano-technology techniques. He has been established first Nano-Technology Research Centre in the Upper Egypt (http://www.aswan.svu.edu.eg/nano/index.htm). He has many of publications which have been published and under published in national, international journals and conferences and held in Nano-Technology Research Centre website.

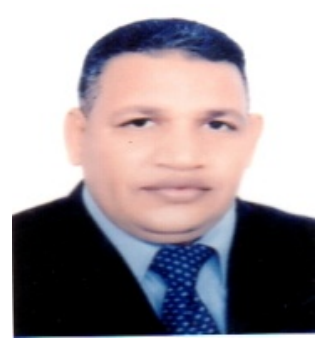

Youssef A. Mobarak was born in Luxor, Egypt in 1971. He received his B.Sc. and M.Sc. degrees in Electrical Engineering from Faculty of Energy Engineering, Aswan University, Egypt, in 1997 and 2001 respectively and Ph.D. from Faculty of Engineering, Cairo University, Egypt, in 2005. He joined Electrical Engineering Department, Faculty of Energy Engineering, Aswan University as a Demonstrator, as an Assistant Lecturer, and as an Assistant Professor during the periods of 1998-2001, 2001-2005, and 2005-2009 respectively. He joined Artificial Complex Systems, Hiroshima University, Japan as a Researcher 2007-2008. Also, he joined Faculty of Engineering, King Abdulaziz University, Rabigh, Saudi Arabia as Associate Professor Position at April 2014 up to date. His research interests are power system planning, operation, optimization, and techniques applied to power systems. Also, his research interests are wind energy, and nanotechnology materials via addition nano-scale particles and additives for usage in industrial field 